015.

\section{Advantages of In-Bone-Venous Channel Infusions for Burned Patients in Extreme Conditions}

\section{N.I. Atuasoff}

Burn Center of Mordovia, Saransk, Russia

The 40 years of practice with more than 12,000 infusions into the bone-venous channel applied to burn victims, in particular, has the following advantages in extreme situations:

1) Immediate application at the prehospital stage due to the needle fixation in the bone. This is important for the injection of anaethetics as well as for heart and respiratory stimulation for treatment of shock;

2) Rendering simultaneous help to many patients by limited medical personnel;

3) Syringe-spiries infusions to the local intra-bone anaesthesia during blood loss;

4) Fluid infusions can be run at rate of up to $150 \mathrm{ml} /$ minute which facilitates reanimatology;

5) The use of novocain administered intra-bone provide anesthesia blockade for burns complicated by bone injuries; The outflow of the intra-bone infusion from within (lavage) at open bone fractures results in mechanical purification of the wounds. No complications have been observed when applying this method at the Burn Center to those patients who sufferred in the catastrophe in Bashkiria in 1989.

\section{0.}

\section{Experience in Treatment of 103 Liver Injuries}

F. Baldoni, M. Finetti, M.F. Lerro, S. Villani, A. Pezzi, L. Cagini, M. Spangaro

Department of General Surgery. Ospedale Maggiore-Bologna, Italy

One hundred three traumatic liver injuries were treated from January 1989 to December 1994 in the Traumatic Emergency Chest and Abdominal Surgery Unit by the General Surgery Division "A" of the Maggiore Hospital in Bologna. Liver injuries were classified according to the New Liver Injury Scale. A total of 23 patients were treated using conservative methods $(22.3 \%) ; 80$ were treated surgically $(77.6 \%)$.

The latter group was subclassified into two groups:

1) Patients with liver injuries of the first and second degree, which were treated with simple reconstructive techniques;

2) Patients with liver injures of the $3 \mathrm{rd}, 4 \mathrm{th}, 5$ th, or 6 th degree that were treated with complex reconstructive techniques.

Overall mortality was $30 \%$ (31 cases). None of the patients who were treated with conservative methods died. Fifteen patients $(14.5 \%)$ died from causes related to the liver injury and $16(15.5 \%)$ for unrelated causes.

In this case review, the authors compare their experience with that of others, and report on the practice acquired in treating the liver injuries that were handled by this method. They describe the solutions adopted, stressing the importance of conservative treatment in selected cases, and particularly the use of packing as a method that occasionally is favored in treating larger liver injuries.
023.

\section{Application of Activated Carbon Fibre Medical Material (ACFM) "Dnieper" in the Treatment of Superficial, 2-3 Degree A Thermal Burns}

I. Korol, S. Volchenko

Burns Department, Kherson Regional Hospital, Ukraine

Along with the general principles of treating patients with second to third degree burns, the use of topical therapy for the burn wounds remains an acute problem. Topical therapy is aimed at:

1) Reducing the rate of cell and plasma mediators of acute, local inflammation, thus decreasing the severity of capillary disturbances and accelerating the recovery of the burned areas;

2) Reducing the penetration rate of tissue and bacterial toxins into the lymphatics and blood, thus decreasing general intoxication, depression of phagocytosis, and non-specific body resistance to infection. This favors reduction of complications, toxic encepaholopathy, etc.; and

3) Reducing the rate of insemination of the burn wounds with infectious agents, thus creating conditions for accelerating the epithelization process in the burn zone.

Our experience with topical application of carbon-adsorbent "Dnieper" for 381 burn patients (including 279 children) with superficial dermal burns provides evidence that this adsorbent meets the requirements noted above, and widens the possibility for achieving positive results when treating superficial dermal burns with severity of II-III A degrees. It also can be used successfully for the local care of superficial burn lesions for both in-patients and out-patients.

\section{5.}

\section{Propofol-A New Way to Provide In-Field Anesthesia}

\section{Dr. Zacher Gábor}

Central Hospital of the Hungarian Army Department of Traumatology Budapest, Hungary

Since 1991, we have been using Propofol for sedation and anesthesia at the Hungarian Rescue Service. We have used it for more than 100 cases. Most of the patients suffered polytraumatic injuries. It also has been used in a few cases for sedation for cardioversion, benzodiazepine-resistant status epilepticus, and for intubation. Two patients were under 14 years old. In a few cases, the blood pressure decreased following administration.

Polytraumatised patients before mobilization receive more than $1,000 \mathrm{ml}$ HAES or polygelatine with ringers lactate solution. For mobilization, long bone reposition, central vein punction, or sedation for ventilation, Propofol could be used in high risk patients in field anesthesia or sedation. The Hungarian Rescue Service was the first ambulance service in the world that used Propofol for in-field anesthesia. 